\title{
A Methodology to Develop the Integration of the Environmental Management System with Other Standardized Management Systems
}

\author{
Manuel Ferreira Rebelo1* ${ }^{*}$, Gilberto Santos ${ }^{1,2}$, Rui Silva1 \\ ${ }^{1}$ CLEGI, Lusíada University, Vila Nova de Famalicão, Portugal \\ ${ }^{2}$ College of Technology, Polytechnic Institute of Cávado and Ave, Barcelos, Portugal \\ Email: ${ }^{*}$ manuel.f.rebelo@gmail.com, gsantos@ipca.pt, rsilva@fam.ulusiada.pt
}

Received 4 July 2014; revised 19 August 2014; accepted 11 September 2014

Copyright (C) 2014 by authors and Scientific Research Publishing Inc.

This work is licensed under the Creative Commons Attribution International License (CC BY). http://creativecommons.org/licenses/by/4.0/

c) (i) Open Access

\section{Abstract}

Traditionally the global management system of an organization is frequently split into a number of individual management systems that are defined and implemented according to specific management systems standards (MSSs) as well as managed independently. The individual implementation of MSSs is an option that leads to several inefficiencies and sub-optimization of the global management system of an organization. As referred by ISO [1] the interested parties' requirements increase. A more effective and efficient option for an organization is to integrate, into an integrated management system (IMS), the implementation and management of requirements of multiple MSSs. Certain difficulties are associated to the structuring process, implementation, verification, evaluation, improvement and progressive development of an IMS in the organizations. Several scholars have proposed various theoretical approaches regarding the integration of individual management systems (MSs) leading to the conclusion that there is not a common practice for all organizations as they encompass different characteristics. This paper aims to present and justify a designed methodology to be used by organizations to support the integration of various MSs. Among them are highlighted: the Environmental Management System (EMS) according ISO 14001 [2], the Quality Management System (QMS) according ISO 9001 [3], and the Occupational Health and Safety Management System (OH \& SMS) according OHSAS 18001 [4]. The methodology was designed in the context of a Portuguese company, on sequence of an organizational diagnosis and a research that was performed through a questionnaire. The strategy and the research methods took into consideration the case study.

${ }^{*}$ Corresponding author. 1st author: Manuel Ferreira Rebelo; 2nd author: Gilberto Santos; 3rd author: Rui Silva. 


\section{Keywords}

\section{Integrated Management Systems (IMS), Environmental Management System (EMS), Quality Management System (QMS), Occupational Health and Safety Management System (OH \& SMS)}

\section{Introduction}

Due to the demand of the market itself or by other internal reasons, there are many organizations that implement different standardized MSs [5]. Standards arise through the development of detailed descriptions of particular characteristics of a product or service by experts from companies and scientific institutions [6]. According to ISO [7], the domain of standardized management systems (MSs) has expanded greatly over the last years and nowadays there exist a relevant number of MSSs for individual MSs, which apply to any type of organization independently of its external and internal context. The objective of the development of standards is to support both individuals and companies when procuring products and services [6]. According to ISO publication [1] a common objective of MSSs is to assist organizations to manage the risks associated with providing products and services to customers and other interested parties.

As the number of MSSs versus standardized MSs increases, their integration becomes a necessity [1] [8]. In the literature and in MSSs are presented several definitions/descriptions of the concept of management system (MS) and integrated management system (IMS). Empirical studies were conducted with the aim of the integration of individualized MSs around the world [9] and several tangible and intangible gains for organizations, as well as to their internal and external interested parties, are achieved with the integration of the individual standardized MSs [10]-[15], among others. Integration of MSs promotes synergies and cost savings, as well as a reduction of the time spent when managing the systems [16]. Olaru [17] summarized forty benefits that an organization can gain from the implementation of an IMS. Organizations therefore need a framework to integrate these MSs and facilitate their contribution to the operation of the overall business MS [18]. On the other hand an essential element in the strategy of any organization is the minimization of business risk to a level that ensures the security market [19]. According to Suditu [20] for organizations that want to survive and compete in the actual market, it is necessary to continually improve performance of their business and MSs in a sustainable way, taking in consideration the necessities of the interested parties. In turn, according to Oliveira [21], integration is justified as a function of the benefits that it provides; certifiable management systems that work separately are more bureaucratic and costly, and generate poorer results than those obtained employing integration. Study conducted by Simon [22] concluded that Organizations prefer integration of MSs to managing them separately and the integration of systems is one of the major strategies for ensuring survival and savings for the organizations of the sample.

Quality is no longer, as formerly, a redundant and restricted concept and must be managed in a global perspective and of sustainability not only focused on satisfying customers, but on a whole range of interested parties [11]. Are example, those identified in the ISO 9004 [7], several others exist. On the other hand, the increasing global competition potentiates, therefore, an increase in the expectations of all the interested parties of organizations. On Table 1 there are listed several interested parties and associated needs and expectations to be satisfied by organizations according to the requirements of related MSSs.

So, more than ever, business sustainability gains increased importance and focus is shifting from their financial results. These results will not verify if that focus does not prioritize also, the satisfaction in a balanced and integrated fashion of customers and others relevant interested parts, that are clearly and objectively the employees for example. In this context of real and new paradigms of management-the Global Quality Management-it is required a constant search for Business Excellence [11].

Hence, in a not distant past, some organizations in Portugal and other countries, although in a small percentage, began to integrate their individual standardized management systems like: EMS; QMS; OH \& SMS; CSRMSCorporate Social Responsibility Management System, among others. For this purpose, organizations began to conceive integrated procedures in order to make the integration of two systems (QMS \& EMS or EMS \& OHSMS) and whenever possible, the three standardized Management Systems: EMS, QMS, and OHSMS [23]. This reveals the growing interest that has been demonstrated by organizations in the adoption of the MSSs ISO 14001, ISO 9001 and OHSAS 18001. 
Table 1. Examples of interested parts and their needs and expectations.

\begin{tabular}{|c|c|}
\hline Interested Parties & Needs and Expectations \\
\hline Customers & Quality; price; delivery performance of products \\
\hline Owners/shareholders & Sustained profitability; transparency \\
\hline People in the organization & Good work environment; job security; recognition and reward \\
\hline Suppliers and partners & Mutual benefits and continuity \\
\hline Society & Environmental protection; ethical behaviour; compliance with statutory and regulatory requirements \\
\hline Competitors & Ethical behaviour; fair competition; zero ethical faults \\
\hline $\begin{array}{l}\text { Government } \\
\text { Labor unions } \\
\text { Regulators }\end{array}$ & $\begin{array}{l}\text { Attractive employer; business continuity; compliance with statutory and regulatory requirements; } \\
\text { energy efficiency; mutual benefits; on time payment of taxes and others fees; } \\
\text { risk management; sustained profitability; transparency }\end{array}$ \\
\hline
\end{tabular}

Note: Adapted and upgraded from ISO [7].

On the other hand, the integration of MSs, supported by those MSSs in a single system, taking into account the correspondence and the level of compatibility between them and potential tangible and intangible gains resulting from this integration will be an added value that organizations cannot ignore [11]. On the other hand, regulations based on ISO 9000 have been created to guide companies in developing systems for management and prevention of worker risks. Annex A and B of ISO 9001 [3] gives various clauses and subclauses related to the necessary elements of this standard [24].

Human resources are the main subject of an organizations activity. Quality improvement and the efficiency of the organization activity depend greatly on the quality of human resources [25]. Top management support and commitment are thus essential for the initiation of the integration process, completed and subsequently maintained. Managers consequently need to recognise that for the IMS to be implemented and maintained, they must continuously push it forward [26]. One interesting finding in research conducted by Alolayan [27] was the fairly strong correlation between top management commitment and the adoption of continuous improvement programs in the work organization. Sustainable management is the combination of management theory and the concept of sustainable development [28], cited by Tsai and Chou [29] and according to Salomone [30], a cultural shift is underway and the number of companies with more than one certification is constantly increasing. Many of them are advancing towards integration.

Within the past decade, the application of certification has spread from documenting quality standards to additional areas, including the management of occupational health and safety (OHS) [31]. To satisfy the requirements of each standardized MSs like: EMS, QMS, and OHSMS organizations have to assure a lot of documented procedures and other documentation, checking processes and associated records forms, among other several paperwork [32]. As stated by Zeng [33] major problems for enterprises to operate multiple parallel MSs include: it causes complexity of internal management, it lowers management efficiency, it incurs in cultural incompatibility and it causes employee hostility and increases management costs. In a recent past, in Portugal and other countries, some companies have begun to integrate their individual MSs [34]. Figure 1 [9] presents the evolution on the number of certifications of integrated MSs (Quality, Environment, and OH \& S) for 2007, 2010, and 2011 in Portugal.

IMSs and its certification are increasingly used by organizations namely to document and develop optimized conformance and business risk management, in a lean and sustainable way, in a variety of different management areas considering, in general, its internal and external context and the needs and expectations of interested parties, in particular. According to Jørgensen [37] the third and most ambitious level, the integration, concerns the creation of a culture of learning, focus on interested parties, continuous improvements, and synergies between the subject areas. This integration creates a sound basis for working towards a more sustainable MS.

\section{Approach to Structuring a Methodology to Develop an IMS}

The standards ISO 14001 [2], ISO 9001 [3] and OHSAS 18001 [4], and the identification of common areas and requirements versus correspondences between them allowed to structure from the existing individual MSs in 


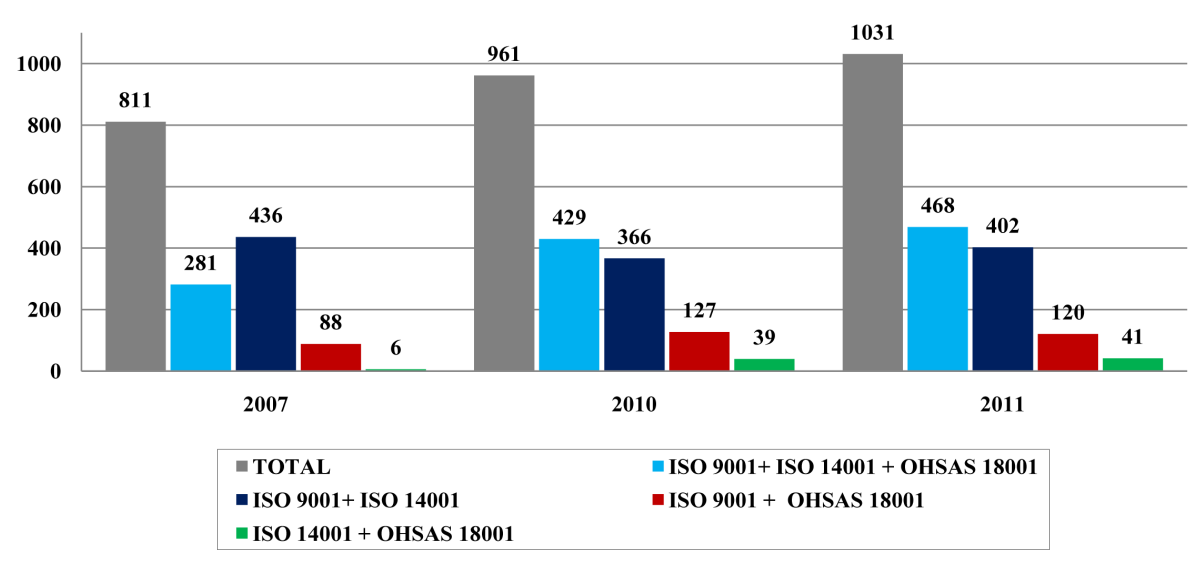

Figure 1. Evolution on the number of certified companies in Portugal related to integrated MSs (Quality, Environment, and OH \& S) for 2007, 2010, and 2011. Source: Data from Portuguese Certified Companies Guide [35] [36].

organizations, a methodology to develop the integration of the EMS with others standardized MSs like QMS and OH \& SMS. There is a convergence in terms of the management model of the standards: ISO 14001 [2], ISO 9001 [3], OHSAS 18001 [4], specifically in terms of the objectives associated with process efficiency, and to the fact that the three MSSs are supported on the continuous improvement principle of the Deming's Cycle-PDCA (Plan/Do/Check/Act), as described in Table 2.

The ISO 14001 [2] specifies requirements for an EMS to enable an organization to develop and implement a policy and objectives which take into account legal requirements and other requirements to which organizations subscribe, and information about significant environmental aspects. It applies to those environmental aspects that organizations identify as those which can be controlled and those which it can be influenced; the ISO 9001 [3] specifies requirements for a QMS where an organization: a) needs to demonstrate its ability to consistently provide products that meet customer and applicable statutory and regulatory requirements; and b) aims to enhance customer satisfaction through the effective application of the system, including processes for continual improvement of the system and the assurance of conformity to customer and applicable statutory and regulatory requirements and the OHSAS 18,001 [4] specifies requirements for an OH \& SMS to enable an organization to develop and implement a policy and objectives which take into account legal requirements and information about OH \& S risks. So, there are several MSSs domains with potential for the effective integration of EMS with QMS and OH\&SMS and integration gives a true usefulness and added value to the organization's business, more easier manageable and securely enhances the improvement of conditions in organizations in terms of management, the prevention component of EMS; QMS and OH \& SMS [11]. According to Santos [23], the compatibility among different MSSs for an effective integration of the individual standardized MSs should be done in moderation and Almeida [38] [39] states that the success of the integration of the MSs is significantly related to the true motivations that leads organizations to integration. To achieve sustained success, top management should establish and maintain a mission, a vision and values for the organization. These should be clearly understood, accepted and supported by people in the organization and, appropriate to other interested parties [7].

\section{Materials and Method}

A preliminary investigation was conducted in the business environment, in a company, localized in the northern region of Portugal. Over the years the company-a SME, has been progressively adopting, in whole or in part, individualized MSSs and others specifications to implement independent MSs. Relevance to the ISO 14001 [2] for the EMS; ISO 9001 [3] for the QMS; OHSAS 18001 [4] for the OH \& SMS, and ISO/International Electrotechnical Commission (IEC) 17025 [40] for Laboratories MS and Accreditation.

While it was imperative to assess the perception of employees of the Company on the methodology, structuring, implementation and evaluation of the integration model of IMS and its validation in a real business environment, it was developed an internal investigation by questionnaire, previously tested and validated, to a representative sample, of employees. Figure 2 shows the distribution of collaborators surveyed from the different levels of the organizational structure. 


\section{Number (percentage) of Collaborators by Hierarchical Level}

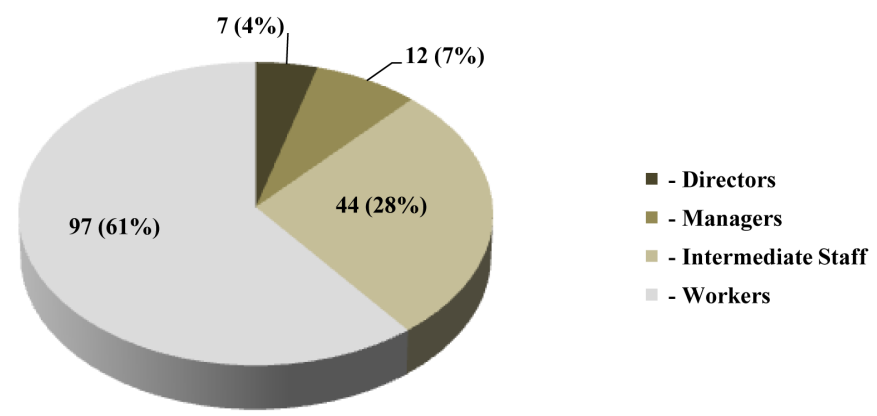

Figure 2. Distribution of collaborators by hierarchical level. Source: [15].

Table 2. PDCA (Plan/Do/Check/Act) convergence at the level of the management model by the correspondent MSSs-ISO 14001 [2], ISO 9001 [3], and OHSAS 18001 [4].

PDCAI Cycle
PLAN
To understanding the context
of the organizations, to establish the
necessary objectives and plans to
achieve them, the processes, and their
sequences and interconnections,
as well as the required criteria and
methods to guarantee their control
and effectiveness

DO

Implement the processes, ensuring the availability of support resources and appropriate documentation and the required documented information for realization and monitoring

\section{CHECK}

Perform the measurements of the processes and monitoring their performance.

Analyze and assess on a regular basis the obtained results

\section{ACT}

Take the needed actions to meet the objectives, achieve the expected results and to encourage improvements

IMPROVE

Continual improvement and innovation of MSs processes

Management Systems Standards

ISO 14001 [2] ISO 9001 [3] OHSAS 18001 [4]

PLANNING

Environmental targets and objectives; identification of environmental aspects and assessment of potential impacts; extent to which material and financial resources are affected; competence, training and awareness of the Human Resources; planning of the activities

\section{IMPLEMENTATION AND OPERATION}

Environmental management programs; control of documents; operational control; emergency preparedness and response

\section{CHECKS AND CORRECTIVE ACTIONS}

Monitoring and measurement; compliance-nonconformities assessment, corrective and preventive actions; records control; internal audits

\section{POLICY}

Environmental aspects; legal and other requirements; environmental policy
RESOURCE

MANAGEMENT

Personnel competence, training and awareness;

material resources; infrastructure and work environment

PRODUCT AND/OR SERVICE REALIZATION Key processes; purchasing; service provision; measurement and monitoring equipment

MEASUREMENT, ANALYSIS AND IMPROVEMENT

Client and employee satisfaction; corrective actions for non-conformities; preventive actions; internal audits

MANAGEMENT

RESPONSIBILITY

Quality policy

Decentralized management; communication and information

\section{PLANNING}

OH \& S objectives; hazard identification and risk assessment; extent to which material and financial resources are affected; training, awareness and competence of the Human Resources; communication, participation and consultation; planning of the activities

\section{IMPLEMENTATION AND OPERATION}

OH \& S management programs; control of documents; operational control; emergency plans

\section{CHECKS AND CORRECTIVE ACTIONS}

Monitoring and measurement; accidents, nonconformities and corrective and preventive actions; records control; internal audits

\section{POLICY}

Hazards and risks; legal and other requirements; $\mathrm{OH} \& \mathrm{~S}$ policy

Continual improvement and innovation of the MSs, with the main objectives of its optimization and satisfaction of all interested parties with focus on them for consequent development and sustained success of the organizations.

Note: Adapted and upgraded from [11] [13].

It was considered a Likert scale on the questionnaire with five levels: 1) irrelevant; 2) not so relevant; 3) relevant; 4) ery relevant; 5) determinant. The population was the total of the collaborators of the company from whom the objective was to draw conclusions about the project objectives and the issues that are being researched. After the questionnaire had been tested and improved in some of its questions, it was sent by e-mail to 
each one the company collaborators of the sample that had been carefully selected according to their position in the hierarchy. The sample considered 49 collaborators, representing $30.62 \%$ of the total collaborators-the population. The responses rate was $86 \%$. In the data collection, analyses and presentation were considered the guidelines of the Portuguese standard-NP 4463 [41].

There were considered four main questions: Question 1-importance of the twelve factors identified as motivation for the implementation of the IMS; Question 2-influence of nine identified interested parties on the performance and evolution of the IMS; Question 3-main difficulties in a group of seven potentials, in the context of the development and implementation of the IMS model. Question 4-potential benefits with the implementation of the IMS-QES.

The main final objective of this preliminary research was to contribute to the integration of EMS, QMS, and OH\&SMS in a specific organizational context, supported on a structured methodology of development of the integration, implementation and evaluation of the designed integration model and its validation. The survey results, by them self, justify, validate and prioritize enormously the structure of the designed methodology and model of IMS.

\section{Matrix of Compatibility of Requirements-Support to Integration}

One of the activities that forms part of the scope and objectives of this preliminary research to which we have paid particular attention is the compatibility of the requirements of the MSSs, in context and framework of the characterization of the company's situation, backed up by an analysis of these MSSs. This compatibility, as presented in Table 3, represent a starting point for consequents activities of integration, simplification and optimization, to achieve a level of the strictly necessary and consequently the three sub MSs-EMS, QMS, and OH \& SMS are integrated to the maximum extent possible.

On the matrix of Table 3 it is shown the requirements of the ISO 14001 [2], ISO 9001 [3], and OHSAS 18001 [4], as well as the established correspondences, made them compatible with each other and associated with the phases of the cycle PDCA-“Plan-Do-Check-Act”. This matrix orientate and align the organizational structure of the enterprise in the same direction and in addition creates a structured and useful referential methodology of work to support an effective alignment and correspondences of the sub management systems of Environment, Quality, and Safety with consequent compatibilities between each other, for consequent design and implementation of the IMS. From this matrix it can also be depicted a correspondence with the PDCA cycle, in this circumstance for the IMS, as well as a set of stages $(1.1 ; 2.1 . .2 .4 ; 3.1 . .3 .7 ; 4.1 \ldots 4.6$ and 5.1$)$ associated with each of the phases of the PDCA cycle.

\section{Model of Development of the IMS}

The continuous improvement of the global performance of an organization is an objective always present in the development of an IMS. The organization should therefore potentiate for each stage: Plan, Do, Check, Act, to be carefully and methodically analyzed in their differences that effectively can be observed in terms of MSSs requirements under clauses equivalent involved and for each phase and each stage of development of the IMS, according to the model of Figure 3 [11] [12], to ensure its compliance and evidence of it, in full conformity.

Organizational diagnosis is an exercise done to check an organization's current health. A complete diagnosis not only checks the current health, but also suggests corrective measures [42]. So, first of all, the understanding of context of an organization, and definition, approval and communication of the integrated management policy, attentive that is common requirement to the different normative references. The leadership of top management is extremely important for the improvement of management quality. If the quality of top management is bad even if the management system of organization is good, it cannot continue to supply good outcomes such as products or services. As a result, it is thought that consequent profit is not ensured [25]. So, top management should demonstrate a strong commitment leadership and personal involvement through a defined Strategy, Policy, Objectives and Targets for Quality, Environment and Safety, as well as, to make available all the needed resources to achieve the objectives [14]. The policy has to be coherent with the Mission, Vision, and Values of the company, these supported on a strategy and specific objectives which in turn, support the implementation of that policy and its consequent effectiveness and continual improvement. The planning of activities in the aim of the Integrated Management System-Phase I-PLAN, is perhaps the most important of all [11] [12]. In fact, a neglected planning, including the non-identification of critical success factors, will lead to inefficiencies that can 
Table 3. Matrix of compatibility of MSSs requirements and of support to the integration of the individual standardized MSs: EMS, QMS, and OH \& SMS.

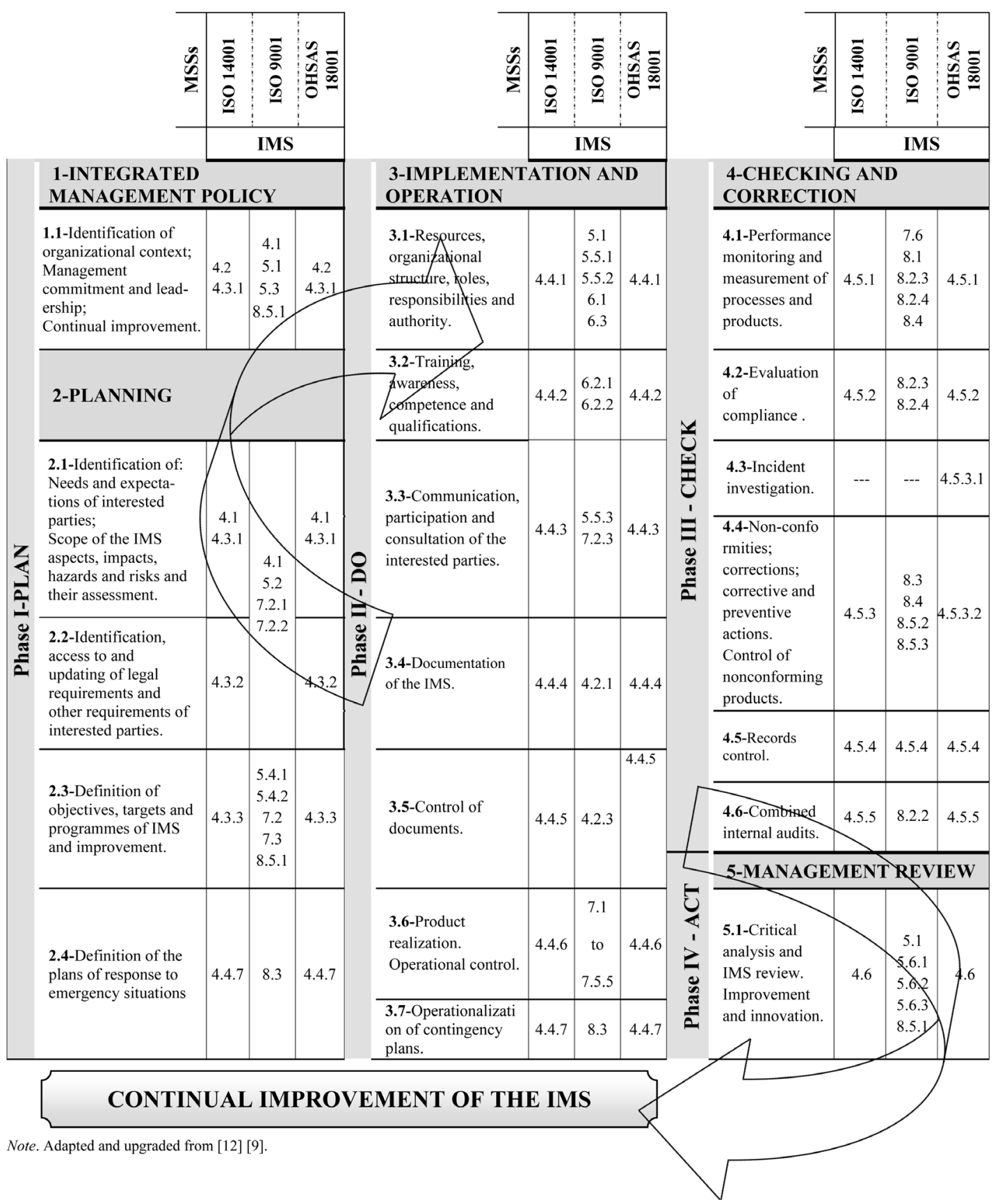

be translated into potential deviations to the objectives and consequent unsuccessful implementation of IMS. It is therefore fundamental to invest resources and expertise at this stage, via a thorough and careful work, in order to respond effectively, within an integrated approach, to all interested parties requirements arising from the involved standards and others applicable specifications, including legal requirements, in this phase of the planning of the IMS with particular focus on environmental issues, customer satisfaction, and occupational health and safety of the collaborators and their families [11] [12].

Following is the Implementation and Operation- "Do", the organization should, in this Phase II—DO, promote the "Make/Do" in coherence with what was previously planned, attentive the scope of the IMS. Corresponds mainly to clauses: 4.4—Implementation and operation of ISO 14001 [2], 7—Product Realization, of ISO 9001 [3], 


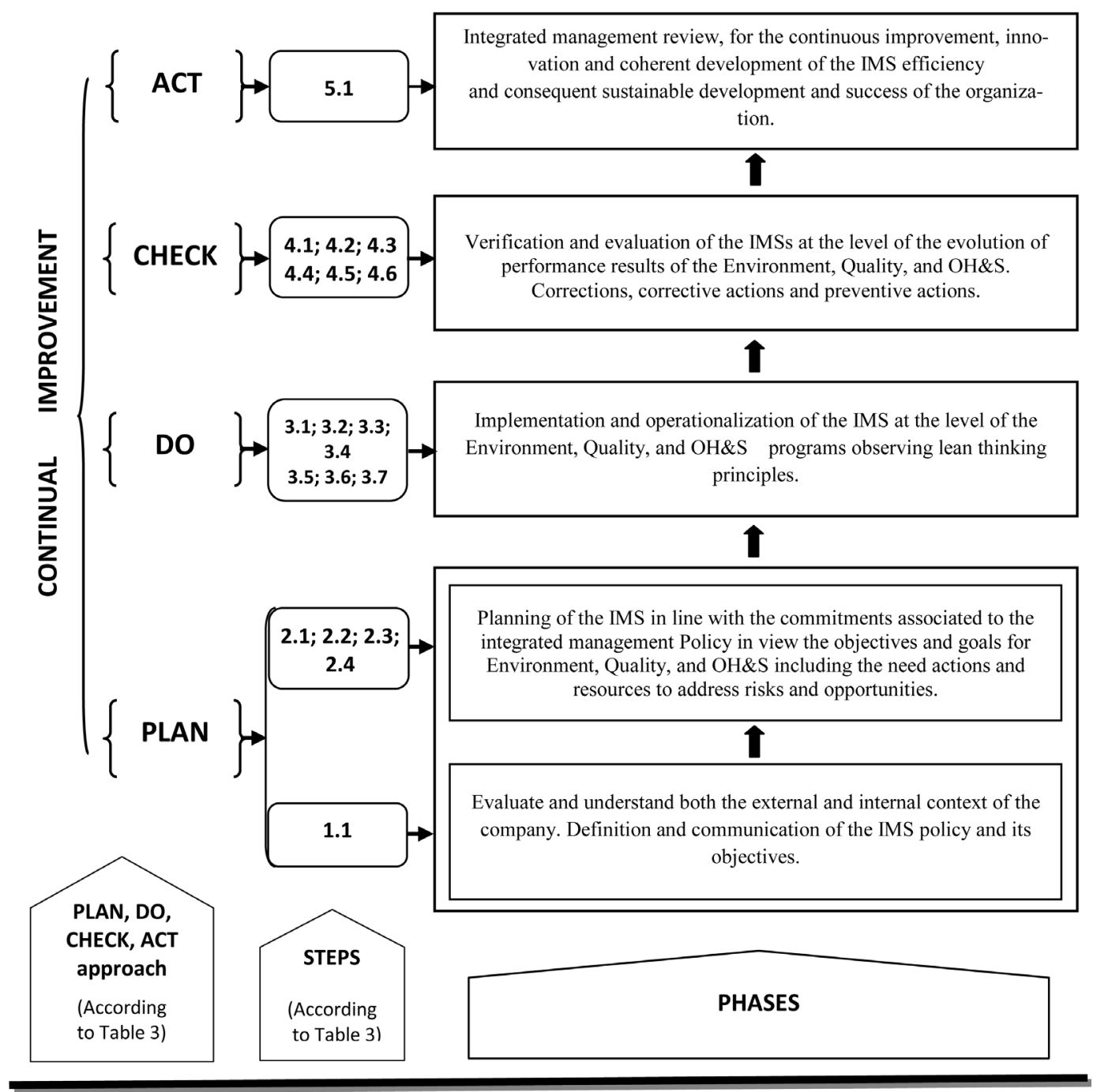

Figure 3. Model of development of the IMS Source: Adapted and upgraded from [11] [12].

and 4.4-Implementation and operation of OHSAS 18001 [4]. In the case of ISO 9001 [3] it should be considered associated with product realization, other complementary clauses, particularly in the context of resource allocation $(6.1,6.2,6.3,6.4)$ and management commitment (5.1, 5.5.1). Different activities of the organization should be set out as processes and put into operation, as per the applicable requirements, in order to strictly comply with the policies and instructions, whether they are documented or not, such as, to ensure that the organization's objectives and targets are achieved and the different Stakeholders are satisfied [14].

In the Phase III-CHECK, are considered six steps (4.1 to 4.6) designed to meet requirements of clauses: 4.5-Checking of the ISO 14001 [2], 8-Measurement, analysis and improvement of ISO 9001 [3], and 4.5-Checking of OHSAS 18001 [4]. With the exception of step 4.3-Investigation of incidents resulting from a specific sub-section, the 4.5.3.1-Incident investigation, the OHSAS 18001 [4] has no correspondence in the ISO 9001 [3] and ISO 14001 [2]. Critical information in the aim of the IMS should be identified, collected and analysed. Consistent with the integrated policy and the commitment to compliance, organization should establish, implement and maintain documented records to demonstrate the improvements and compliance with all the applicable internal and external requirements. The use of KPIs - key process indicators, to monitor the processes, their control and continual improvement should be made systematically and guaranteed by the process owners, through the active involvement and participation of collaborators [14]. Particular relevance for the internal and external combined audits of the different components and areas of the IMS, and suppliers and subcontractors. Audits shall be scheduled at a frequency that takes into account the risk of the business. It must be conducted to 
assess the level of implementation and compliance of the IMS, its evolution, effectiveness and potentiate the identification of the necessary corrections and opportunities for improvement, which must be listed and prioritized on its evaluation and implementation [14] [15].

Finally, in the Phase IV-ACT, it was identified step 5.1-Critical analysis and review of the integrated management system, which refers to requirements of clauses: 4.6-Management review of ISO 14001 [2], 5.6Management review of ISO 9001 [3], and 4.6-Management review of OHSAS 18001 [4]. Top management should ensure that processes of assessment, improvement and innovation on the different components of the management system. Management reviews should be conducted at planned intervals, to identify opportunities for improvements based namely in the lean philosophy, to assess the need for modifications to the IMS and to the integrated management policy, to ensure that it continues to be appropriate, suitable, effective and efficient [14]. Top management should review the integrated management system, defining the review inputs according to the requirements of each MSSs. Management review requires, in itself, a very careful preparation phase, particularly, to the level of various information that supports the inputs [11] [12]. Records of the management review should be retained [2]-[4].

\section{Discussion and Conclusions}

Management systems standards have developed in an unprecedented manner in the last few years. There exist at least, one for each interested part and new ones are going to be published. There is no international ISO standard with a specific structural model for Integrated Management Systems for Quality, Environment and Safety, or for other management areas such as: Risk Management; Information Security Management; RDI Management; and Social Responsibility Management, among others. The impact generated by environmental, quality, and safety and other MSSs is demonstrated by the importance of such standards worldwide, ISO 14001 [2], ISO 9001 [3], and OSHAS 18001 [4]. Organizations have to understand its context, the needs and expectations of interested parties and associated requirements, and consequently to determine the scope of the integrated management system, and formalise a policy to be communicated to internal and external interested parties.

The continuous improvement of global performance of organizations must be always a present goal in a perspective of sustainability [43]. The development methodology to integrate various sub-management systems supported on a model of integration of the EMS, QMS, and OH \& SMS at organizations should therefore potentiate, for each phase: Plan, Do, Check, Act, a careful and methodical analysis of the differences that effectively are observed at the level of normative requirements under the equivalent clauses and for each step of their development as the advocated model of integration.

Making MSSs requirements compatible through the analysis of their similarities promotes integration and can be depicted from the compatibility matrix presented-ISO14001 [2], ISO 9001 [3], and OHSAS 18001 [4], establishing correspondences, matching them with each other and associate the following phases of the PDCA cycle-Plan, Do, Check, Act: Policy and principles; Planning, Implementation and Operation, Performance Evaluation, Improvement, Management Review. This is one of the activities that in the aim and objectives of the integration model was given special attention in context of characterization and framework of the situation diagnosed in the company in which the research was conducted. That compatibilization constitutes, the starting point for subsequent activities of integration, simplification and optimization, to a level of the strictly necessary and consequent integration maximized as desired of the three individual MSs-EMS, QMS, and OH \& SMS, in context of strong competitiveness and changing of the business environments, which occurs at an accelerated and turbulent manner, enhancing also the sustained development of the business with added value for the relevant interested parts.

The integration of the three individual MSs represent added value both in the present and, fundamentally, for the future, not only for the company, as well as for a whole range of interested parties [43]. Examples are also highlighted by the surveyed respondents: the elimination of conflicts between individual systems with optimization of Resources; the improvement at the level of the coordinated and integrated management of the risk associated to the safety of the persons and company assets, environment and quality of the products; the reduction on the number of internal and/or external audits and audits to suppliers, and spent time versus associated costs; the creation of added value for the business through the elimination of several types of waste.

From the statistical analyses, resulting from the responses to the survey, there are shown a set of conclusions that by them self reveal: the importance, presently and for the future, of various "motivating factors" that were evaluated and alone justify and validate the model of implementation of the integration of the EMS, QMS, and 
$\mathrm{OH} \& \mathrm{SMS}$ in the company, either from internal aspects such as rationalization and optimization of resources, reduction of costs and bureaucracy; otherwise from external aspects, such as increasing competitiveness, to satisfy the growing demands of customers and others stakeholders. There were also identified a relevant number of difficulties, as well as a range of potential benefits resulting from the integration of the EMS, QMS, and OH \& SMS into an IMS.

One of the major problems that organizations are facing with the integration of several MSSs is regarding the conception of a methodology and the implementation of an adequate structure of IMS to overcome the problems resulting from multiple MSSs. The continuous improvement of the global performance of organizations must be always a present goal in a perspective of sustainability and the route that should be taken by maximizing the integration of the several individual MSs [13], supported in an model of IMS, flexible, integrator and lean [15].

\section{Acknowledgements}

This work had the financial support of the Portuguese Foundation for the Science and Technology (FCT) through the Strategic Project-UI 4005-2014, Project Reference PEst-OE/EME/UI4005/2014.

\section{References}

[1] International Organization for Standardization (ISO) (2008) The Integrated Use of Management System Standards. International Organization for Standardization, Geneva.

[2] International Organization for Standardization (ISO) (2004) ISO 14001: Environmental Management Systems. Requirements with Guidance for Use. 2nd Edition, ISO Copyright Office, Geneva.

[3] International Organization for Standardization (ISO) (2008) ISO 9001: Quality Management Systems-Requirements. 4th Edition, ISO Copyright Office, Geneva.

[4] British Standards Institution (BSI) (2007) BS OHSAS 18001: Occupational Health and Safety Management Systems-Requirements. 2nd Edition, BSI Limited, London.

[5] Karapetrovic, S. and Casadesus, M. (2009) Implementing Environmental with Other Standardized Management Systems: Scope, Sequence, Time, and Integration. Journal of Cleaner Production, 17, 533-540. http://dx.doi.org/10.1016/j.jclepro.2008.09.006

[6] Disterer, G. (2013) ISO/IEC 27000, 27001 and 27002 for Information Security Management. Journal of Information Security, 4, 92-100. http://dx.doi.org/10.4236/jis.2013.42011

[7] International Organization for Standardization (ISO) (2009) ISO 9004: Managing for the Sustained Success of an Organization-A Quality Management Approach. 3rd Edition, ISO Copyright Office, Geneva.

[8] Bernardo, M., Casadesus, M., Karapetrovic, S. and Heras, I. (2009) How Integrated Are Environmental, Quality, and Other Standardized Management Systems? An Empirical Study. Journal of Cleaner Production, 17, 742-750. http://dx.doi.org/10.1016/j.jclepro.2008.11.003

[9] Rebelo, M.F., Santos, G. and Silva, R. (2014) Integration of Individualized Management Systems (MSs) as an Aggregating Factor of Sustainable Value for Organizations: An Overview through a Review of the Literature. Journal of Modern Accounting and Auditing, 10, 357-384.

[10] Khanna, H.S., Laroiya, S.C. and Sharma, D.D. (2010) Integrated Management Systems in Indian Manufacturing Organizations: Some Key Findings from an Empirical Study. The TQM Journal, 22, 670-686. http://dx.doi.org/10.1108/17542731011085339

[11] Rebelo, M.F. (2011) Contribution to the Structuring of a Model of Integrated Management System QES. Master Thesis, Polytechnic Institute of Cávado and Ave, Barcelos.

[12] Santos, G., Rebelo, M.F., Barros, S. and Pereira, M. (2012) Certification and Integration of Environment with Quality and Safety-A Path to Sustained Success. In: Curkovic, S., Ed., Sustainable Development-Authoritative and Leading Edge Content for Environmental Management, InTech, Croatia, 193-218. http://dx.doi.org/10.5772/48414

[13] Rebelo, M.F. and Silva, R.G. (2012) Integration of Individual Management Systems_-An Organizational Pillar for the Competitiveness and the Sustainability of Business. The International Conference on Innovation for Sustainability-IS 2012, Porto, 27-28 September 2012, 1-12.

[14] Rebelo, M.F., Santos, G. and Silva, R. (2014) A Generic Model for Integration of Quality, Environment and Safety Management Systems. TQM Journal, 26, 143-159. http://dx.doi.org/10.1108/TQM-08-2012-0055

[15] Rebelo, M.F., Santos, G. and Silva, R. (2014) Conception of a Flexible Integrator and Lean Model for Integrated Management Systems. Total Quality Management \& Business Excellence, 25, 683-701. http://dx.doi.org/10.1080/14783363.2013.835616 
[16] Simon, A., Bernardo, M., Karapetrovic, S. and Casadesus, M. (2011) Integration of Standardized Environmental and Quality Management Systems Audits. Journal of Cleaner Production, 19, 2057-2065. http://dx.doi.org/10.1016/j.jclepro.2011.06.028

[17] Olaru, M., Maier, D., Nicoara, D. and Maier, A. (2014) Establishing the Basis for Development of an Organization by Adopting the Integrated Management Systems: Comparative Study of Various Models and Concepts of Integration. Procedia-Social and Behavioral Sciences, 109, 693-697. http://dx.doi.org/10.1016/j.sbspro.2013.12.531

[18] Asif, M., Bruijn, E.J., Fisscher, O.A.M. and Searcy, C. (2010) Meta-Management of Integration of Management Systems. The TQM Journal, 22, 570-582. http://dx.doi.org/10.1108/17542731011085285

[19] Nowicki, P. (2013) Risk Management-An Important Issue in Quality Management Systems. The 7th International Quality Conference, Kragujevac, 24 May 2013, 267-272.

[20] Suditu, C. (2007) Positive and Negative Aspects Regarding the Implementation of an Integrated Quality-Environmental-Health, and Safety Management System. Annals of the Oradea University, Fascicle of Management and Technological Engineering, 6, 2013-2017.

[21] De Oliveira, O.J. (2013) Guidelines for the Integration of Certifiable Management Systems in Industrial Companies. Journal of Cleaner Production, 57, 124-133. http://dx.doi.org/10.1016/j.jclepro.2013.06.037

[22] Simon, A., Bernardo, M., Karapetrovic, S. and Casadesus, M. (2013) Implementing Integrated Management Systems in Chemical Firms. Total Quality Management and Business Excellence, 24, 294-309. http://dx.doi.org/10.1080/14783363.2012.669560

[23] Santos, G., Mendes, F. and Barbosa, J. (2011) Certification and Integration of Management Systems: The Experience of Portuguese Small and Medium Enterprises. Journal of Cleaner Production, 19, 1965-1974. http://dx.doi.org/10.1016/j.jclepro.2011.06.017

[24] Vinodkumar, M.N. and Bhasi, M. (2011) A Study on the Impact of Management System Certification on Safety Management. Safety Science, 49, 498-507. http://dx.doi.org/10.1016/j.ssci.2010.11.009

[25] Esaki, K. (2013) General Frame Work of New TQM Based on the ISO/IEC25000 Series of Standard. Intelligent Information Management, 5, 126-135. http://dx.doi.org/10.4236/iim.2013.54013

[26] Zeng, S.X., Xie, X.M., Tam, C.M. and Shen, L.Y. (2011) An Empirical Examination of Benefits from Implementing Integrated Management Systems (IMS). Total Quality Management and Business Excellence, 22, 173-186. http://dx.doi.org/10.1080/14783363.2010.530797

[27] Alolayan, S., Hashmi, S., Yilbas, B. and Hamdy, H. (2013) An Empirical Evaluation of the ISO 9001 Quality Management Systems for Certified Work Organizations in Kuwait as Benchmarked against Analogous Swedish Organizations. Journal of Service Science and Management, 6, 80-95. http://dx.doi.org/10.4236/jssm.2013.61009

[28] Daub, C.H. and Ergenzinger, R. (2005) Enabling Sustainable Management through a New Multi-Disciplinary Concept of Customer Satisfaction. European Journal of Marketing, 39, 998-1012. http://dx.doi.org/10.1108/03090560510610680

[29] Tsai, W.H. and Chou, W.C. (2009) Selecting Management Systems for Sustainable Development in SMEs: A Novel Hybrid Model Based on DEMATEL, ANP, and ZOGP. Expert Systems with Applications, 36, 1444-1458. http://dx.doi.org/10.1016/j.eswa.2007.11.058

[30] Salomone, R. (2008) Integrated Management Systems: Experiences in Italian Organizations. Journal of Cleaner Production, 16, 1786-1806. http://dx.doi.org/10.1016/j.jclepro.2007.12.003

[31] Granerud, L. and Rocha, R.S. (2011) Organisational Learning and Continuous Improvement of Health and Safety in Certified Manufacturers. Safety Science, 49, 1030-1039. http://dx.doi.org/10.1016/j.ssci.2011.01.009

[32] Karapetrovic, S. and Jonker, J. (2003) Integration of Standardized Management Systems: Searching for a Recipe and Ingredients. Total Quality Management \& Business Excellence, 14, 451-459. http://dx.doi.org/10.1080/1478336032000047264

[33] Zeng, S.X., Shi, J.J. and Lou, G.X. (2007) A Synergetic Model for Implementing an Integrated Management System: An Empirical Study in China. Journal of Cleaner Production, 15, 1760-1767. http://dx.doi.org/10.1016/j.jclepro.2006.03.007

[34] Santos, G., Barros, S., Mendes, F. and Lopes, N. (2013) The Main Benefits Associated with Health and Safety Management Systems Certification in Portuguese Small and Medium Enterprises Post Quality Management System Certification. Safety Science, 51, 29-36. http://dx.doi.org/10.1016/j.ssci.2012.06.014

[35] Cempalavras, Comunicação Empresarial (2012) Portuguese Certified Companies Guide. 7th Edition. http://www.cempalavras.pt/GEC_2012/EN/index.html

[36] Cempalavras, Comunicação Empresarial (2013) Portuguese Certified Companies Guide. 8th Edition. http://www.cempalavras.pt/GEC_2013/EN/index.html 
[37] Jørgensen, T.H. (2008) Towards More Sustainable Management Systems: Through Life Cycle Management and Integration. Journal of Cleaner Production, 16, 1071-1080. http://dx.doi.org/10.1016/j.jclepro.2007.06.006

[38] Almeida, J., Sampaio, P. and Santos, G. (2012) Integrated Management Systems-Quality, Environment, and Health and Safety: Motivations, Benefits, Difficulties, and Critical Success Factors. Book of Abstracts, The International Symposium on Occupational Safety and Hygiene-SHO 2012, Guimarães, 9-10 March 2012, 13-15.

[39] Almeida, J., Domingues, P. and Sampaio, P. (2014) Different Perspectives on Management Systems Integration. Total Quality Management and Business Excellence, 25, 338-351. http://dx.doi.org/10.1080/14783363.2013.867098

[40] International Organization for Standardization/International Electrotechnical Commission [ISO/IEC] (2005) ISO/IEC 17025: General Requirements for the Competence of Testing and Calibration Laboratories. ISO Copyright Office, Geneva.

[41] Instituto Português da Qualidade (2009) NP 4463: Linhas de orientação sobre técnicas estatísticas para a ISO 9001: 2000 (ISO/TR 10017:2003). Instituto Português da Qualidade, Caparica.

[42] Saeed, B. and Wang, W. (2014) Sustainability Embedded Organizational Diagnostic Model. Modern Economy, 5, 424431. http://dx.doi.org/10.4236/me.2014.54041

[43] Rebelo, M.F. and Santos, G. (2012) Integration of the Occupational Health and Safety Management System with the Quality Management System and Environmental Management System-From the Theory to the Action. Book of Abstracts, The International Symposium on Occupational Safety and Hygiene-SHO 2012, Guimarães, 9-10 March 2012, 372-374. 
Scientific Research Publishing (SCIRP) is one of the largest Open Access journal publishers. It is currently publishing more than 200 open access, online, peer-reviewed journals covering a wide range of academic disciplines. SCIRP serves the worldwide academic communities and contributes to the progress and application of science with its publication.

Other selected journals from SCIRP are listed as below. Submit your manuscript to us via either submit@scirp.org or Online Submission Portal.
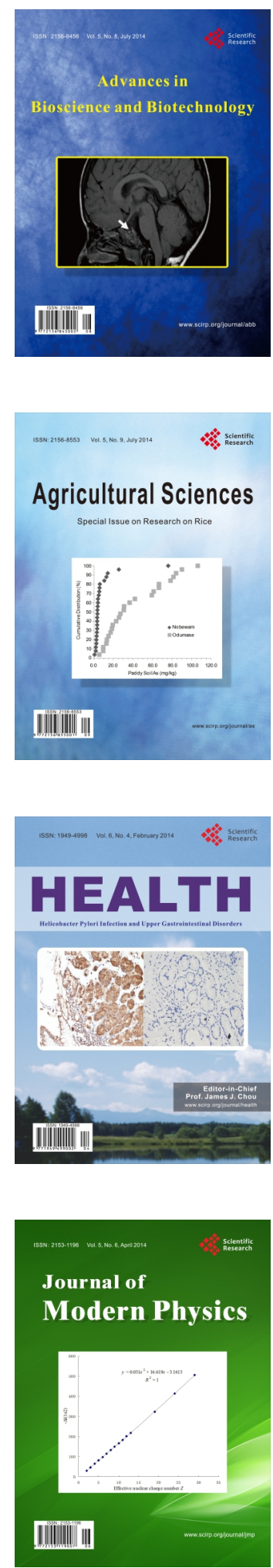
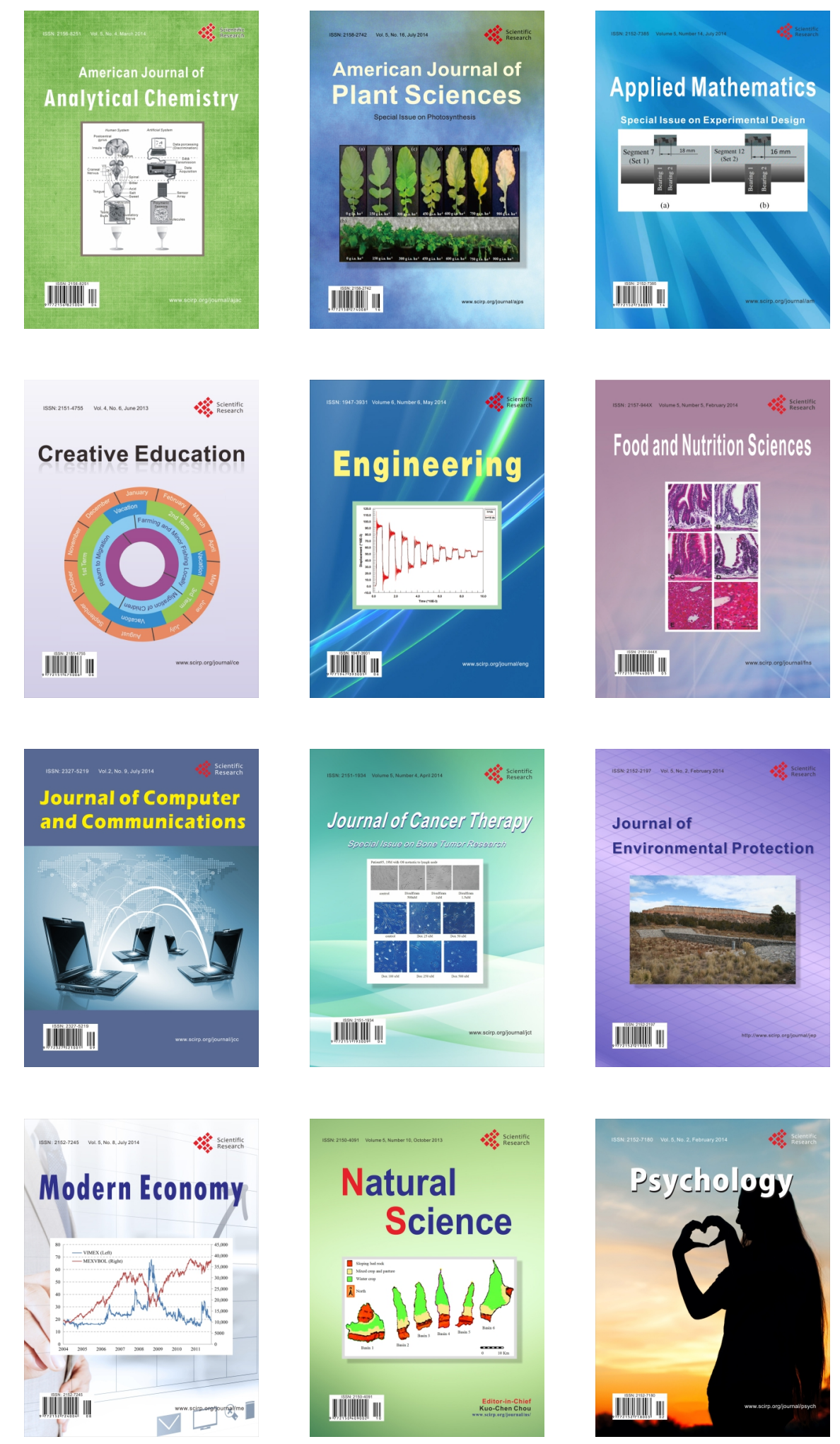